\title{
Market Power in Canadian Beef Packing
}

\author{
James Rude, ${ }^{1}$ Darryl Harrison ${ }^{2}$ and Jared Carlberg ${ }^{3}$ \\ ${ }^{1}$ Department of Rural Economy, University of Alberta, 569 General Services Building, \\ Edmonton, Alberta T6G 2H1 (corresponding author: phone: 780-492-4890; \\ fax: 780-492-0268; e-mail: James.Rude@ualberta.ca). \\ ${ }^{2}$ Victoria Farmers Federation, 24 Collins Street, Melbourne, Australia \\ (phone: 6103-9207-5522; fax: 6103-9207-5500; e-mail: dharrison@rff.org.au). \\ ${ }^{3}$ Department of Agribusiness and Agricultural Economics, University of Manitoba, \\ 372 Dafoe Road, Winnipeg, Manitoba R3T 2N2 (phone: 204-474-9827; \\ fax: 204-261-7251; e-mail: jared_carlberg@hotmail.com).
}

\begin{abstract}
Concentration levels in Canadian beef packing have increased dramatically over the last two decades, raising concerns about the possible use of market power in cattle procurement markets. This paper uses establishment-level data to test the hypothesis that Canadian beef packers use oligopsony power to pay lower prices for cattle than those which would prevail in a competitive market. A four-equation econometric system is estimated using generalized method of moments. No evidence is found that beef packers behaved in an anticompetitive manner on a national basis when procuring cattle during the period examined. This reinforces conclusions reached by previous studies using different data sets and estimation methods. However, given the lack of assurances that the U.S. slaughter market will remain open to Canadian cattle exporters, regulators must remain vigilant in monitoring the procurement practices of beef packers. There is also a need for greater levels of data disaggregation to allow fed and cull cattle procurement markets to be studied separately, perhaps even on a regional basis.
\end{abstract}

Les niveaux de concentration dans l'industrie de l'abattage du bruf au Canada ont augmenté considérablement au cours des deux dernières décennies, ce qui laisse craindre l'exercice possible de pouvoir de marché sur les marchés d'approvisionnement de bovins. Dans le présent article, nous avons utilisé des données d'entreprises pour vérifier l'hypothèse selon laquelle les entreprises de transformation du bruf au Canada exerceraient un pouvoir d'oligopsone pour se procurer des bovins à des prix moins élevés que ceux qui prévaudraient dans un marché concurrentiel. Nous avons estimé un système économétrique de quatre équations à l'aide de la méthode des moments généralisés (GMM). Nous n'avons trouvé aucune preuve permettant de croire que les transformateurs de viande de bæuf au Canada se sont comportés de façon anticoncurrentielle lorsqu'ils se sont approvisionnés en bovins durant la période couverte par l'étude. Nos conclusions renforcent celles d'études antérieures réalisées à partir de données et de méthodes d'estimation différentes. Toutefois, compte tenu de l'incertitude quant à l'ouverture de l'industrie étatsunienne de l'abattage aux exportateurs de bovins canadiens, les organismes de réglementation doivent surveiller avec vigilance les pratiques d'achats des transformateurs de bœuf. Il faudrait également effectuer une désagrégation des données plus poussée pour étudier séparément les marchés d'approvisionnement de bovins engraissés et de bovins de réforme, et ce, peut-être même à l'échelle régionale.

\section{INTRODUCTION}

Concern about market power in Canadian meat packing has been a consistent theme for almost a century (see MacLachlan 2001). Over the last 15 years, the four-firm concentration ratio for cattle slaughter has increased from $54 \%$ to $93 \%$ as a result of industry

Canadian Journal of Agricultural Economics 00 (2010) 1-16

DOI: $10.1111 /$ j.1744-7976.2010.01204.x 
consolidation and a series of acquisitions (AAFC 2008). This increased level of concentration has raised concerns about the potential for beef packers to exercise oligopsony power in their procurement of cattle. Compared with the substantial body of research measuring market power in the U.S. beef packing industry (see Azzam and Anderson 1996 and Ward 2002 for surveys of this research), a similar body of research for Canada has not materialized. Over the last 10 years, there have only been four studies of market power in Canadian meat packing: one with respect to pricing of outputs (Cranfield and Goddard 1999), and three with respect to procurement prices (Quagrainie et al 2003; Love 2005; Church and Gordon 2007).

There are at least two possible reasons for the relatively smaller volume of Canadian research. One is recognition that pricing behavior in Canadian cattle procurement markets is disciplined by the opportunity to sell live animals to U.S. packers. A second potential reason relates to the relative lack of publicly available data with which to conduct the research. The potential for a competitive market was eroded when in May 2003 the U.S. border was closed to imports of Canadian cattle as a result of the bovine spongiform encephalopathy (BSE) discovery in Alberta. The border did not open to trade in fed cattle under 30 months of age until July of 2005, and trade in older animals did not resume until November of 2007. The border closure spawned two nonpublished studies on conduct in the Canadian meat packing sector pre- and post-BSE: Love (2005), which was commissioned by Industry Canada's Competition Bureau; and Church and Gordon (2007), which was funded by the beef industry.

Data limitations can influence how research is done in important ways. In the United States, the Grain Inspection, Packers, and Stockyards Administration (GIPSA) of the USDA provides useful data including annual reports that track detailed information for structural characteristics, purchases by animal class and market types, contracting arrangements, packer financial performance, and periodic special studies on meatpacking concentration and market power. GIPSA has also, on occasion, made microtransactionlevel data available for detailed studies of the market.

By contrast, Canadian data are much more limited in terms of unit of aggregation, spatial aggregation, and breadth of information. The major source is Statistics Canada's Annual Survey of Manufactures (ASM) and Logging, which provides data for North American Industry Classification System (NAICS) categories 31161 (animal slaughterexcept poultry) and 31114 (rendering and processing) (Statistics Canada 2009a). However, using these data for empirical purposes is challenging for three reasons: it is aggregated over beef and pork; the classification system and available information has been subject to periodic change, ${ }^{1}$ and the data are aggregated to annual averages of provincial and national data. Given these data limitations, it is little wonder so few studies of Canadian beef packers have been conducted. Of the four studies cited above, all used aggregate data with the exception of Church and Gordon (2007), who used weekly feedlot-specific data

\footnotetext{
${ }^{1}$ Prior to 1998, the ASM was grouped into industries based on the Standard Industrial Classification with a survey of the most important establishments in an industry. In 1998, the classification system changed to NAICS. In 2000, the target population was expanded to cover all manufacturing units. At the end of 2003, the ASM was replaced with the Annual Survey of Manufactures and Logging and these changes also fundamentally affected the type of information available. As a result of this change, commodity data from 2004 onward cannot be readily compared with data published for previous periods (see Statistics Canada 2009b).
} 
for net revenues, weights, number of cattle, and types. They were able to obtain lot-specific transactions prices for fed steers and heifers plus weekly market data for cut-out values of grade AAA and AA beef. The authors parameterized processing costs by using an outside estimate of operating costs for large efficient plants running at full capacity.

The objective of the research reported in this paper is to use a previously unexploited data source to determine whether Canadian beef packers behave in a noncompetitive manner and reduce live cattle price to levels below those that would prevail under competitive market conditions. This study is unique in that it uses firm-level data from the Statistics Canada ASM from 1992 to 2001, which includes firm-level observations of meat packing revenues as well as the cost structure of individual firms. To that end, this work begins to fill a research void in microlevel analysis of market power in Canadian cattle procurement. Although the period examined predates BSE and two other studies have examined the effect of the border closure, this study is nevertheless important in that it utilizes a unique data set not employed by any previous studies. Another contribution of the study is that it reaffirms the estimates of market power by Love (2005) and Church and Gordon (2007).

\section{BACKGROUND}

The Canadian beef packing sector involves a few large beef packing firms and many smaller abattoirs, and is part of a vertically related meat marketing and distribution system. Abattoirs are designed for small-scale cattle slaughter, have little mechanization and are highly labor intensive. Large packing firms are also labor intensive but have a considerable degree of mechanization to ensure high throughput. Multinational packers treat their Canadian plants as part of a larger network that requires management to use Canadian-sourced cattle in ways that complement and coordinate but not necessarily compete with their U.S.-based plants. The major beef packers then operate where an available supply exists, with two of the top three beef packing plants in Canada residing in Alberta; the other is in southern Ontario. Over the estimation period, two firms (Cargill and Lakeside Packers) dominated beef packing, each with a slaughter capacity of over 4,500 head/day. The second tier of packers consisted of Guelph-based Better Beef (now owned by Cargill) and Alberta/Saskatchewan-based XL Foods (which now owns Lakeside Packers), which had a daily capacity of 1,500-2,000 head per day. A third tier of packers includes much smaller companies: St. Helens Meat Packers (400 head per day) and Ryding Regency Packers (200 head per day) in Toronto, and a number of regional packers, such as the now-closed Hub Meat Packers of Moncton. In 2007, Cargill and Lakeside Packers accounted for $67 \%$ of Canadian beef packing capacity (NFU 2008). It is the highly concentrated nature of the industry plus localized cattle supplies that may provide the packers with conditions that may be conducive to the exercise of some degree of market power.

Packers purchase Canadian cattle from both independent and vertically integrated feedlots, as well as from small-to-medium-sized beef cattle operations. In turn, they sell processed beef (mainly in the form of boxed beef) and by-products to further processors and downstream wholesalers. There is thus the potential for packers to exert market power in both procurement (oligopsony) and sales (oligopoly) markets, although large purchasers in the latter market may be able to offset market power to a certain extent. Although the study of market power in the product market is an interesting issue, the 
consequences of oligopsony power may be more profound given the limited options for feedlots, and the fact that seemingly small changes in margins may make a substantial difference to livestock producers and rival meatpacking firms operating on the edge of remaining viable. The exercise of market power in the sale of beef is limited by the availability of other substitute meats and from competition from imports of boxed beef.

\section{MODEL}

Characterization of market power in the input sector involves comparing the price of the input (live cattle) to its associated marginal valuation and determining whether the procurement price has been marked down from the competitive level. The hypothesis is that buyers are able to adjust the quantity purchased below competitive levels in order to lower the price by exploiting the upward-sloping cattle supply function. This can be demonstrated using a profit-maximizing framework, and assuming the beef packers are price takers in the output market and the noncattle input markets. The profit function for a beef packer is

$$
\max _{X_{j}^{c} X_{j}^{n c}} \pi=P Q_{j}-W^{c}\left(X^{c}\right) X_{j}^{c}-W^{n c} X_{j}^{n c} \quad \text { subject to } \quad Q_{j}=f\left(X_{j}^{c}, X_{j}^{n c}\right)
$$

which gives firm $j$ 's level profit as the difference between revenues and costs, where costs are associated with a cattle input $\left(X^{c}\right)$ and noncattle inputs $\left(X^{n c}\right)$. Because beef packers are not necessarily price takers in fed cattle markets, $W^{c}$ varies with the level of each firm's cattle purchases. Firms are, however, price takers in the markets for noncattle inputs (fuel and electricity and labor). The first-order condition for profit maximization with respect to cattle purchases by firm $j$ is then

$$
\frac{\partial \pi}{\partial X_{j}^{c}}=P \frac{\partial Q_{j}}{\partial X_{j}^{c}}-W^{c}-X_{j}^{c} \frac{\partial W^{c}}{\partial X^{c}} \frac{\partial X^{c}}{\partial X_{j}^{c}}=0
$$

The first term on the right-hand side of Equation (2) is the value of marginal product (VMP). In a competitive industry, this measure of incremental profitability would be equated to the marginal factor cost (MFC), in this case the price of cattle. However, in a noncompetitive industry, the MFC will adjust with input use. The final term of Equation (2) shows how firm $j$ 's cattle procurement affects purchases by the overall meat packing industry (conjectural variation), and this in turn affects the price of cattle, which is then multiplied by the input quantity.

After manipulation, Equation (2) can be rewritten in terms of elasticity measures

$$
P \frac{\partial Q}{\partial X_{j}^{c}}=W^{c}\left(1+\frac{1}{\varepsilon} \cdot \theta_{j}\right)
$$

where the elasticity of cattle supply is $\varepsilon$, and the market power parameter (conjectural elasticity) is $\theta_{j}$. The conjectural elasticity is the ratio of the proportional change in industry cattle procurement to the proportional change in cattle purchases by firm $j$. In a competitive market, $\theta$ is equal to zero, while in the case of a monopsonist, $\theta=1$. Accordingly, this parameter will fall in the range between zero and one. 
In order to estimate Equation (3), it is necessary to develop an econometric model that will identify the value of the marginal product while equating it to the firm's MFC. This study exploits the duality of the firm's production technology and a profit function. The restricted form of a generalized Leontief profit function (Diewert 1973) is selected as a second-order approximation to a profit function on the assumption that not all factors of production are instantaneously adjustable. This approach distinguishes between the variable inputs and the quasi-fixed inputs, which may not be at optimal levels at any given time and which only partially adjust toward their full equilibrium levels within one time period. The firm's capital stock and purchases of cattle are treated as quasi-fixed factors. Morrison Paul (2001, p. 66) justifies treating cattle purchases in this manner because "(t)his facilitates explicit characterization of the sequential nature of the optimization process" and additional purchases require increased capacity utilization, which is also quasi-fixed. Contraction of cattle slaughter is limited, in the shorter term, by contractual arrangements. $^{2}$

Equation (4) is the restricted profit equation for Canadian beef packing firms. Profit is specified as a function of the prices of output, labor, and energy, along with the quantities of cattle and capital employed. The profit function also incorporates fixed effects for individual firms included through slope differentials across firms through dummy variables (the $D U M_{f}$ in Equation (4)) associated with the quantity of cattle input purchased (see Morrison Paul 2001 for a similar procedure). The firm dummy variable was included in the profit function to allow for firm-specific influences on input decisions and input pricing, especially to separate the impact that the largest firms and regionally dispersed firms may have on the market. The eight largest (based on sales) beef packing firms each received a dummy identification in the estimation process.

Using a generalized Leontief profit function as a second-order approximation to the indirect value function, the profit function can be specified as

$$
\begin{aligned}
\pi= & \beta_{p p} \cdot P+\beta_{l l} \cdot W^{l}+\beta_{e e} \cdot W^{e}+2 \cdot \beta_{p l} \cdot\left(P \cdot W^{l}\right)^{1 / 2}+2 \cdot \beta_{p e}\left(P \cdot W^{e}\right)^{1 / 2} \\
& +2 \cdot \beta_{l e}\left(W^{l} \cdot W^{e}\right)^{1 / 2}+\varphi_{k k} K^{2}+\left(C \cdot \sum_{f} \cdot \gamma_{c c f} D U M_{f}\right)^{2} \\
& +2 \cdot\left(K \cdot C \cdot \sum_{f} \gamma_{k c f} \cdot D U M_{f}\right) \\
& +\varphi_{p k} \cdot(P \cdot K)+\left(P \cdot C \cdot \sum_{f} \varphi_{p c f} \cdot D U M_{f}\right)+\varphi_{l k}\left(W^{l} \cdot K\right) \\
& +\left(W^{l} \cdot C \cdot \sum_{f} \varphi_{l c f} D U M_{f}\right)+\varphi_{e k}\left(W^{e} \cdot K\right)+\left(W^{e} \cdot C \cdot \sum_{f} \varphi_{e f} \cdot D U M_{f}\right)
\end{aligned}
$$

\footnotetext{
${ }^{2}$ Schroeder and Ward (2006) estimate that over the estimation period captive arrangements covered between $32 \%$ and $40 \%$ of steer and heifer slaughter for Alberta's three largest beef packers.
} 
where $\pi=$ profit, $P=$ output price, $W^{l}=$ wage rate, $W^{e}=$ price of energy, $K=$ capital stock, and $C=$ quantity of cattle processed. Note this profit function specification imposes symmetry and the generalized Leontief form imposes homogeneity. Applying Hotelling's lemma yields the system of output supply and variable input demand equations for labor and energy given by Equations (5) through (7)

$$
\begin{aligned}
& Q=\frac{\partial \pi}{\partial P}=\beta_{p p}+\beta_{p l}\left(W^{l} / P\right)^{1 / 2}+\beta_{p e}\left(W^{e} / P\right)^{1 / 2}+\phi_{p k}(K)+C \cdot\left(\sum_{f} \phi_{p c f} D U M_{f}\right) \\
& -X^{l}=\frac{\partial \pi}{\partial W^{l}}=\beta_{l l}+\beta_{p l}\left(P / W^{l}\right)^{1 / 2}+\beta_{l e}\left(W^{e} / W^{l}\right)^{1 / 2}+\phi_{l k}(K)+C \cdot\left(\sum_{f} \phi_{l c f} D U M_{f}\right) \\
& -X^{e}=\frac{\partial \pi}{\partial W^{e}}=\beta_{e e}+\beta_{p e}\left(P / W^{e}\right)^{1 / 2}+\beta_{l e}\left(W^{l} / W^{e}\right)^{1 / 2}+\phi_{e k}(K)+C \cdot\left(\sum_{f} \phi_{e c f} D U M_{f}\right)
\end{aligned}
$$

To account for the possibility of market power with respect to cattle procurement, Equation (3) requires that the MFC is equated with the VMP of cattle purchases. The VMP is the shadow value $\partial \pi / \partial C$ or the derivative of the restricted profit function with respect to the quasi-fixed factor cattle purchases (Murray 1995; Morrison Paul 2001) and this expression is then substituted into Equation (3), yielding the following:

$$
\begin{aligned}
W^{c}(1+\theta / \varepsilon)= & \frac{\partial \pi}{\partial C}=2 \cdot K \cdot\left(\sum_{f} \varphi_{k c f} \cdot D U M_{f}\right)+2 \cdot C \cdot\left(\sum_{f} \varphi_{c c f} \cdot D U M_{f}\right) \\
& +P \cdot\left(\sum_{f} \varphi_{q c f} \cdot D U M_{f}\right)+W^{l} \cdot\left(\sum_{f} \varphi_{l c f} \cdot D U M_{f}\right) \\
& +W^{e} \cdot\left(\sum_{f} \varphi_{e c f} \cdot D U M_{f}\right)
\end{aligned}
$$

Equations (5) to (8) comprise the system to be estimated. Solving for $\theta$ requires knowledge of the cattle market supply elasticity $\varepsilon$, which for this study is imposed based on a prior estimate of that parameter. Packers face a common industry supply curve and even if market power exists in the industry, firms have no influence over this function. The market power parameter is likely to vary over time and may depend on the ability of domestic cattle producers to find alternative outlets for their cattle sales and the structural nature of the industry. It is hypothesized that domestic market power is a function of the 
ratio of Canadian live cattle exports to total sales volume. ${ }^{3}$ The conjectural elasticity can be determined as

$$
\theta=\theta_{o}+\theta_{1}(\text { export volume/sales volume })
$$

Equation (9) can be substituted into Equation (8) and included in the system for econometric estimation. One issue that arises in estimation of the system in Equations (5)-(8) is the possible endogeneity of the quantity of cattle, meat prices, and the ratio of exports to shipments, all of which appear as explanatory variables in this system. This problem could be addressed with nonlinear three-stage least squares; however, the use of pooled data can cause additional problems with autocorrelation and heteroskedasticity, and it would be desirable to obtain panel-corrected standard errors. ${ }^{4}$ Keene and Runkle (1992) have advocated a generalized method of moments (GMM) approach for panel data with endogenous right-hand side variables.

A GMM approach involves the estimation of a set of orthogonality conditions, which are the product of the instruments $(z)$ and the errors from each estimated equation in the system $\left(E\left[Z^{\prime} \varepsilon\right]=0\right)$. The estimation process involves two steps: the first involves threestage least squares to obtain preliminary estimates of the parameters. These estimates are used to obtain residuals to obtain a variance-covariance matrix of the orthogonality conditions. In the second stage, this estimate of the variance-covariance matrix is inserted into $(Y-X \beta)^{\prime} Z\left(Z^{\prime} W Z\right)^{-1} Z^{\prime}(Y-X \beta)$ and the expression is minimized to obtain the GMM estimates, where $Y$ is the dependent variable, $X$ is a matrix of regressors, $Z$ is a matrix of instruments, and $W$ is a weighting matrix. The weighting matrix $W$ accounts for correlations among the orthogonality conditions when the error terms are not independent and identically distributed. There are as many GMM estimators as there are choices of weighting matrix, but GMM provides a unifying framework that nests familiar estimators (e.g., ordinary least squares, generalized least squares, and instrumental variable estimation) as special cases. The optimal weighting matrix that provides the most efficient estimate is the inverse of the variance-covariance matrix (Hansen 1982). In this case, a heteroskedasticity-autocorrelation consistent estimate of the variance-covariance matrix is computed with Newey-West (1987) procedure that employs a Bartlett kernel smoothing technique to weight the autocovariances. These estimates are efficient given the moment conditions.

The establishment of a set of suitable instruments is always problematic because it requires that the instruments are both relevant (correlated with the endogenous regressors) and exogenous (not correlated with the error terms). Theory suggests that exogenous

\footnotetext{
${ }^{3}$ Previous studies (Murray 1995; also Schroeter 1988, and others) have suggested that a linear regression could be used to help determine $\theta$. The traditional regressors included in such a model are concentration, degree of sunk costs, and transportation (for spatially defined markets), among others. Including exports as a ratio of domestic sales was the method employed to account for the cyclical nature of the cattle industry.

${ }^{4}$ An alternative would be to employ the multiple-equation, fixed effects panel data method suggested by Blackwell (2005); however, this approach only estimates a system of linear seemingly unrelated regression and does not address simultaneity problems so this approach was abandoned. Lagrange multiplier tests for heteroskedasticity confirmed a problem for each of the equations.
} 
shifters of supply and demand will determine price movements but not be affected by other factors in the model. For instance, Kesavan and Buhr (1995) use the prices of corn and soy meal, the Consumer Price Index for food, industrial product price indexes, and interest rates as instruments in a model of price determination for U.S. meat products. This study follows this approach by using these variables as excluded instruments plus all of the exogenous explanatory variables in the system act as the remaining instrumental variables (quantity of cattle, meat prices, and the ratio of exports to shipments are considered endogenous explanatory variables). ${ }^{5}$

\section{DATA}

The data used in this study are pooled over time (10 years) and across firms (eight), totaling 80 observations. This approach is not typical of most studies of the beef packing sector, which are either purely time series (e.g., Azzam 1997) or cross-sectional (e.g., Morrison Paul 2001). The approach used here allows the researcher to study the dynamics of change with a short time series using repeated observations of sufficient cross-sections. The combination of time series with cross-sections can enhance the quality and quantity of data in ways that would be impossible using one of these two dimensions.

The primary source of data was Statistics Canada's (ASM microdata). ${ }^{6}$ The ASM is a survey of the manufacturing industries of Canada conducted annually since 1917; its current population size is approximately 100,000 manufacturing establishments. Questionnaires of these establishments collect data for about 12,000 commodities classified according to the Standard Classification of Goods (SCG). Establishment information obtained from the ASM is grouped according to the NAICS; the NAICS code used for this study is from Animal Slaughter (except poultry) (311611). ${ }^{7}$ The official definition of 311611 consists of "establishments primarily engaged in slaughtering animals, except poultry and small game. Establishments that slaughter animals and then prepare meat products are included" (Statistics Canada 2007, p. 127). However, this classification is too broad for this study because it includes both pork and beef packers. Detailed establishment-level information allows for accurate identification and removal of firms not involved in beef packing; the separation was accomplished using reported SCG inputs and outputs. Only data on firms listing bovine inputs and outputs were included in the study, using only data for the top eight firms, which were in business for the entire sample period. Firms were selected on the basis of cattle purchases.

Output quantities in kilograms are available for fresh and chilled carcasses by enterprise. Although price data for a number of individual products are available, different firms provide combinations of prices. Rather than attempting to aggregate these prices, a

\footnotetext{
${ }^{5}$ Given a short time series of data, the practice of using lagged endogenous variables as instruments was not be followed.

${ }^{6}$ The data were obtained through a special arrangement with Statistics Canada while the second author was an employee with that agency. The data are confidential, and under the agreement, cannot be reproduced or made available for public release.

${ }^{7}$ The NAICS code 311614 includes establishments that process meat from a carcass. These firms were not included in this study because they are not involved in the relationship between cattle producers and processors. Although their position in the value added chain is very important, it is not relevant to this input side study.
} 
unit value of output was calculated by dividing the total value of shipments by total output. Wages are obtained by dividing manufacturing wages and salaries by manufacturing employment for each firm. The AMS provides expenditures on fuel and electricity for each firm. The price of energy is constructed with Consumer Price Indexes for electricity and fuel, and the same energy price is applied to all firms. The quantity of fuel and electricity is obtained by dividing firm-specific fuel and electricity expenditures by the energy price index.

Firm-level capital expenditures were not available from the ASM, so a proxy for capital expenditures was used. In CANSIM table 290009 V754881, Statistics Canada provides estimates of capital expenditures for meat product manufacturing (Statistics Canada 2008). These expenditures were then prorated using firm-specific output market shares. Input demand is measured in kilograms of cattle purchased by each firm. The price of cattle is determined for each firm by dividing the expenditure on animals divided by the quantity of inputs.

Given the pooled nature of the ASM data, it is not feasible to concurrently estimate a cattle supply equation using a similar data format ${ }^{8}$ in order to use cross-equation restrictions to identify the cattle supply elasticity in Equation (8). Rather, the value of the cattle supply elasticity is imposed based on prior estimates. Azzam (1997) estimated the own-price cattle supply elasticity to be 0.844 and this is the value used in this study. A sensitivity analysis of the value of supply elasticity is reported in the results section, and in terms of the overall market power parameter $\theta$ the results are not very sensitive to the size of the elasticity estimate.

\section{RESULTS}

Data for the top eight firms are used to estimate Equations (5)-(8). Although there are important structural differences among firms, input-output ratios are similar as are patterns of output and input prices. Firm-specific dummy variables are included in each equation to establish slope differential effects for individual firms in each estimated equation. For confidentiality reasons, these firm-specific dummies are not shown; average parameter values and their associated standard errors are provided instead. The parameter results are presented in Table 1.

The $t$-ratios reported in Table 1 were calculated based on standard errors from a heteroskedasticity-consistent variance-covariance matrix (Newey and West 1987). In addition to adjusting for heteroskedasticity, the estimator uses weighted cross-products of the residuals to account for autocorrelation. The weighting formula is based on a Bartlett kernel with three autocorrelation terms. ${ }^{9}$ The resulting $t$-ratios indicate mixed results for the significance of the $\beta_{i j}$ parameter estimates. The parameter for beef supply with respect to wages is significant at the $1 \%$ level while the parameter with respect to energy prices is only significant at the $20 \%$ level. Both parameters are negative, implying input price increases result in decreased meat production. The cross-price effects between labor (energy) demand and energy prices (wages) both have statistically insignificant relationships. Significant input-output coefficients $\left(\beta_{l l}\right.$ and $\left.\beta_{e e}\right)$ indicate a technology

\footnotetext{
${ }^{8}$ Measuring supply response for cattle typically involves modeling an entire system including all stages of cattle production from breading inventories to the supply of slaughter animals.

${ }^{9} \mathrm{~A}$ rule of thumb is to set the order of autocorrelation to fourth root of the number of observations.
} 
Table 1. Generalized method of moments parameter estimates, beef equation system

\begin{tabular}{|c|c|c|c|}
\hline Parameter & Estimate & Parameter & Estimate \\
\hline$\beta_{p p}$ & $\begin{array}{r}-5,733.41 \\
(-0.69)\end{array}$ & $\phi_{l t}$ & $\begin{array}{r}-119.25 \\
(-2.98)\end{array}$ \\
\hline$\beta_{p l}$ & $\begin{array}{r}-7,914.68 \\
(-2.23)\end{array}$ & $\beta_{e e}$ & $\begin{array}{c}-38.05 \\
(-1.94)\end{array}$ \\
\hline$\beta_{p e}$ & $\begin{array}{r}-156.65 \\
(-1.29)\end{array}$ & $\phi_{e k}$ & $\begin{array}{l}-4.13 \mathrm{E}-04 \\
(-3.02)\end{array}$ \\
\hline$\phi_{p k}$ & $\begin{array}{c}0.04 \\
(1.02)\end{array}$ & $\phi_{\text {ecavg }}{ }^{\mathrm{a}}$ & $\begin{array}{l}-6.82 \mathrm{E}-05 \\
(-0.67)\end{array}$ \\
\hline$\phi_{\text {pcavg }}{ }^{\mathrm{a}}$ & $\begin{array}{r}0.59 \\
(15.8)\end{array}$ & $\phi_{\text {ccavg }}{ }^{\mathrm{a}}$ & $\begin{array}{l}-9.57 \mathrm{E}-06 \\
(-3.07)\end{array}$ \\
\hline$\beta_{l l}$ & $\begin{array}{c}233,474 \\
(2.98)\end{array}$ & $\phi_{c k}$ & $\begin{array}{l}2.60 \mathrm{E}-06 \\
(1.79)\end{array}$ \\
\hline$\beta_{l e}$ & $\begin{array}{c}6.64 \\
(0.22)\end{array}$ & $\theta_{0}$ & $\begin{array}{c}0.31 \\
(2.84)\end{array}$ \\
\hline$\phi_{l k}$ & $\begin{array}{l}-2.25 \mathrm{E}-03 \\
(-0.89)\end{array}$ & $\theta_{1}$ & $\begin{array}{l}-1.26 \\
(-2.83)\end{array}$ \\
\hline$\phi_{\text {lcavg }}{ }^{\mathrm{a}}$ & $\begin{array}{c}0.024 \\
(2.30)\end{array}$ & & \\
\hline$R^{2}$ for output equation & 0.99 & $R^{2}$ for labor demand & 0.75 \\
\hline$R^{2}$ for energy demand & 0.72 & $R^{2}$ for pricing equation & 0.71 \\
\hline Hansen's $J$-test ${ }^{\mathrm{b}}$ & 0.48 & & \\
\hline
\end{tabular}

Notes: $t$-ratios are shown in parentheses.

${ }^{\text {a }}$ Parameters for individual firms are not given; these variables are averaged across all firms.

${ }^{\mathrm{b}} p$-value for test of overidentifying restrictions $\left(\mathrm{H}_{0}\right.$ : all instruments are exogenous).

that is closer to fixed than variable proportions. The effect of the quasi-fixed factor, cattle $\left(\phi_{i c}\right)$, is statistically significant for all equations except energy demand. The effect of the quasi-fixed factor, capital $\left(\phi_{i k}\right)$, is insignificant for the beef supply, labor demand, and cattle pricing equations, but is significant for the energy demand equation.

The validity of the instrumental variables used with the GMM procedure depends on two requirements: they must be correlated with the included endogenous variables and orthogonal to the error process. The former can be tested by examining the joint significance of the full set of instruments in the first stage in determining the endogenous variables. Stock and Watson (1997) suggest a rule of thumb that $F$-statistics over 10 signify a relevant set of instruments. The $F$-statistics for all reduced-form equations for the endogenous variables easily pass this test. Since the number of external instruments (prices of corn and soy meal, Consumer Price Index for food, industrial product price index [manufacturing], and prime rate) exceeds the number of endogenous regressors (quantity of cattle, meat prices, and the ratio of exports to shipments), a test of overidentifying restrictions can be used to test if the instruments are exogenous. In the context of GMM, the overidentifying restrictions may be tested with the $J$-statistic of Hansen (1982). This statistic is the objective function used to estimate the GMM estimator and the null hypothesis is that the orthogonality conditions are sufficiently satisfied so that the objective 
Table 2. Own- and cross-price elasticities, output supply and input demand

\begin{tabular}{lccc}
\hline & Beef & Labor & Energy \\
\hline Beef & 0.008 & -0.008 & -0.003 \\
& $(2.32)$ & $(-2.22)$ & $(-1.29)$ \\
Labor & 1.74 & -1.73 & -0.007 \\
& $(2.23)$ & $(-2.24)$ & $(0.22)$ \\
Energy & 0.47 & -0.05 & -0.41 \\
& $(1.29)$ & $(0.22)$ & $(-0.74)$ \\
\hline
\end{tabular}

Note: $t$-ratios are shown in parentheses.

function is minimized and the instruments can be considered independent of the error structure. The $J$-statistic is distributed as $\chi^{2}$ with the number of degrees of freedom equal to the total number of moment conditions less the number of regressors. A rejection of the null hypothesis implies that the instruments do not satisfy the orthogonality conditions and are therefore not exogenous. The $J$-test produces a probability $\operatorname{Pr}\left(\chi^{2}(15)-14,55\right)=$ 0.48 so the null hypothesis cannot be rejected.

Monotonicity is satisfied for the beef supply and the factor demand equations. For a well-behaved profit function, the regularity conditions are that the function is convex in prices (inputs and outputs) and concave in quasi-fixed inputs. When evaluated at the data means (both for the entire sample and yearly means), all three eigenvalues for the Hessian of the profit function are positive, implying the function is convex in prices and the resulting supply curve slopes up and the factor demands slope down. A negative semidefinite matrix of second derivates of profits with respect to quasi-fixed factors is consistent with profit maximization. The curvature of this function depends on $\Sigma_{f} \phi_{c c f}$, which is negative $(-0.002)$ and statistically significant. ${ }^{10}$ So, as the shadow value of cattle prices decreases, as the number of cattle increases and that is indicative of profitmaximizing behavior.

Table 2 gives own- and cross-price elasticities of output supply and input demand. The profit function is well-behaved in that own-price elasticities are negative in factor demands and positive in output. The elasticity of labor demand is slightly more elastic $(-1.75)$ than the value of -1.05 found by Quagrainie et al (2003). The own-price elasticity for energy is negative but not significantly different from zero.

The own-price beef elasticity is positive and statistically different from zero, but nonetheless is very small and less than 0.1 . This is consistent with the expected size for a short-run supply elasticity when the most important factor of production (cattle) is treated as quasi-fixed. The own-price elasticity of demand, for the cattle input, cannot be determined due to the restricted profit model assumption.

Although the $\beta_{i j}$ s are symmetric, the resulting cross-price elasticities are not symmetric because points of evaluation change as the dependent variable changes. The cross-price elasticity for labor and energy is negative and insignificant. The cross-price elasticities for beef supply with respect to the input prices are negative (with a significant coefficient

\footnotetext{
${ }^{10}$ The complete matrix includes a term $\phi_{k k}$ that is not estimated because a second shadow price equation for the quasi-fixed capital stock was not estimated due to data limitations.
} 
Table 3. Conjectural elasticity estimates

\begin{tabular}{|c|c|c|c|c|}
\hline \multirow[b]{2}{*}{ Parameter } & \multirow[b]{2}{*}{ Estimate } & \multicolumn{3}{|c|}{ Sensitivity analysis } \\
\hline & & $\begin{array}{c}\varepsilon=0.844 \\
\theta / \varepsilon=\text { Lerner index }\end{array}$ & $\begin{array}{c}\varepsilon=0.6 \\
\text { Estimate }\end{array}$ & $\begin{array}{l}\varepsilon=1.0 \\
\text { Estimate }\end{array}$ \\
\hline$\theta_{92}$ & $\begin{array}{r}0.007 \\
(0.09)\end{array}$ & 0.008 & 0.005 & 0.008 \\
\hline$\theta_{93}$ & $\begin{array}{l}-0.005 \\
(-0.07)\end{array}$ & -0.006 & -0.004 & -0.006 \\
\hline$\theta_{94}$ & $\begin{array}{c}0.000 \\
(0.00)\end{array}$ & 0.000 & 0.000 & 0.000 \\
\hline$\theta_{95}$ & $\begin{array}{l}-0.030 \\
(-0.44)\end{array}$ & -0.036 & -0.022 & -0.036 \\
\hline$\theta_{96}$ & $\begin{array}{l}-0.060 \\
(-0.93)\end{array}$ & -0.071 & -0.043 & -0.071 \\
\hline$\theta_{97}$ & $\begin{array}{l}-0.015 \\
(-0.21)\end{array}$ & -0.018 & -0.011 & -0.018 \\
\hline$\theta_{98}$ & $\begin{array}{c}0.001 \\
(0.002)\end{array}$ & 0.002 & 0.001 & 0.002 \\
\hline$\theta_{99}$ & $\begin{array}{r}0.080 \\
(0.82)\end{array}$ & 0.095 & 0.057 & 0.095 \\
\hline$\theta_{00}$ & $\begin{array}{r}0.077 \\
(0.80)\end{array}$ & 0.092 & 0.055 & 0.092 \\
\hline$\theta_{01}$ & $\begin{array}{l}0.015 \\
(0.19)\end{array}$ & 0.018 & 0.011 & 0.018 \\
\hline$\theta_{\text {average }}$ & $\begin{array}{r}0.007 \\
(0.09)\end{array}$ & 0.008 & 0.005 & 0.008 \\
\hline
\end{tabular}

Note: $t$-ratios are given in parentheses, and are the same for sensitivity analysis elasticity estimates (third and fourth columns) given assumed supply elasticities.

with respect to labor but not for energy), which is expected since output should decline as input prices rise. The cross-price effects for labor and energy demand with beef output price are positive (with again labor significant but not energy), which is consistent with profit maximization.

Turning to the central issue of oligopsony power, Table 1 shows that the market power parameters $\theta_{0}$ and $\theta_{1}$ are both significantly different from zero. The intercept term $\theta_{0}$ shows the conjectural elasticity abstracting from the effects of exports, while $\theta_{1}$ explains how the ability to export live cattle reduces the ability of packers to exercise oligopsony power. The negative coefficient $(-1.26)$ on the ratio of exports to shipments has the effect of eliminating any exercise of market power. Table 3 shows yearly simulations of the conjectural elasticity after applying Equation (9) to these market conduct parameters. The offsetting effect on the market power parameter holds regardless of the elasticity of cattle supply. The two far right columns of Table 3 show sensitivity analysis when the supply elasticity is decreased to 0.6 and increased to 1 . 
The parameters in Table 3 are not significantly different from zero, implying that beef packing firms have behaved competitively when procuring cattle with an average conjectural elasticity of 0.007 and a Lerner index $\left(\theta / \varepsilon=\left(V M P-w^{c}\right) / w^{c}\right)$ percentage mark-down of $0.8 \%$ below the value of the marginal product.

These results are consistent with previous research. Quagrainie et al (2003) used aggregate industry data to find a test statistic for a Lerner index $(\theta / \varepsilon)$ and found very small values between 0.01 and 0.02 for the time period most consistent with this study (1992-97). Despite different frequencies of data and levels of aggregation (aggregate annual versus firm-specific panel), time periods (1960-97 versus a 1992-2001 panel), sources of data, and functional forms (translog versus restricted generalized Leontief profit functions), the two studies produce remarkably consistent results.

The results of this study are also consistent with two post-BSE studies. The conjectural elasticity estimated by Love (2005) for the pre-BSE period was -0.034 ( $0.02 p$-value) for fed cattle and 0.198 (0.004 $p$-value) for cull cattle; the pre-BSE conjectural elasticity number reported by Church and Gordon (2007) was 0.0003 , which is not statistically different from zero.

While this study was not estimated for the post-2001 period, its results can nevertheless be used to draw inferences with respect to the impact of a closed border. In the post-BSE period, Love (2005) reports a postevent market power parameter of -0.023 (0.329 $p$-value) for fed cattle and 0.585 ( $0.005 p$-value) for cull cattle. Church and Gordon (2007) estimate a post-BSE market power parameter of 0.254 (39.41 $t$-ratio). These estimates show that considerably more market power was exercised when the border was closed. In this study, the statistically significant parameter $\theta_{0}=0.31$ (Table 1 ), shows the conjectural elasticity when abstracting from the ability of Canadian cattle producers to export. Accordingly, this parameter should be roughly comparable with the post-BSE market power parameters of the two studies just mentioned. This study does not differentiate between cull and fed cattle. As expected, $\theta_{0}$ falls between Love's (2005) postevent cull and fed cattle market power parameters and the parameter is roughly consistent with Church and Gordon's post-BSE market power estimate.

Studies conducted on oligopsony power exercised in the U.S. meat packing industry have found conjectural elasticities ranging from zero to just less than $0.2 .{ }^{11}$ Given the low estimated measures of market power in U.S. beef packing, it is unlikely that a significant degree of market power could be exercised in Canada if the potential for live exports exists. Ward (2002, p. 2) notes that most U.S. studies found a price distortion of less than $3 \%$, yet he cautions "even seemingly small impacts on a $\$ / \mathrm{cwt}$. basis may make a substantial difference to livestock producers and rival meatpacking firms operating at the margin of remaining viable or being forced to exit an industry." This note of caution is likely equally applicable in a Canadian content, even with an average price distortion of less than $1 \%$, due to the yearly variability of the ratio of live exports to total slaughter cattle supplies and corresponding impact on the Lerner index plus the potential threat of future border closures.

\footnotetext{
${ }^{11}$ These estimates include: Muth and Wohlgenant (1999) - 0.0; Morrison Paul (2001) - 0.0004; Azzam and Park (1993) - 0.032; Schroeter (1988) - 0.042; and Azzam and Pagoulatos (1990) 0.178 .
} 


\section{CONCLUSIONS}

This study developed an econometric model using establishment-level data from Canada's ASM to determine the existence and extent of market power in the procurement of cattle by the Canadian beef packing industry. Results suggest there is little evidence of oligopsony market power with an open border; it was not found that Canadian plants are paying less at the margin for cattle than would be justified by the incremental profitability of an additional cattle purchase. This contradicts the commonly held belief that a highly concentrated industry will exercise market power. However, this finding is consistent with previous studies, which also could not find the exercise of market power as long as Canadian feedlots and other exporters had the option of shipping live cattle to the United States.

These other studies do, however, find evidence of the exercise of market power after the closure of the U.S. border to live cattle exports. This study predicts that a cessation of live exports would result in a $37 \%$ discount in procurement cattle prices from competitive levels. This discount should be put into context: in the first few months after the U.S. border closed to Canadian imports, fed cattle prices fell by roughly $40 \%$ and cull cattle prices fell by more than $70 \%$ (CanFax 2009).

The major implication of a noncompetitive beef packing sector, with associated lower cattle prices, is reduced profits for the cattle producers and increased exposure for publicly funded income stabilization programs. Market power may also create the potential for packers to capture a portion of government-funded compensation payments. Hence, there is a strong incentive for the government to promote and maintain a competitive packing industry. A competitive industry can be fostered with increased marketing options for cattle producers. This certainly includes promoting unfettered trade in live animals and beef.

One of the limitations of this study is that it does not explicitly measure market power during the ebbs and flows of the cattle cycle. For example, Koontz and Garcia (1997) formulate a noncooperative game where firms collude when ample cattle supplies are available and pay low prices, however, when cattle supplies are tighter, the market enters a noncooperative phase during which high prices are paid. Carlberg et al (2009) discovered periods of collusive and reversionary behavior in an experimental market for fed cattle using a finite mixture estimation approach. Applying this approach in a Canadian context would be informative. While this study examines firm-specific data, it does not distinguish between fed steers and heifers from cull cows and bulls. Future research should attempt to analyze disaggregate fed from cull cattle as well as employing more recent microlevel data. Last, given trends toward use of captive supplies by packers, policy makers should consider mandating the availability of detailed data on packer procurement practices. Among other things, this could facilitate more precise study of regional/spatial competitiveness in Canadian beef packing.

\section{ACKNOWLEDGMENT}

The authors extend thanks to CJAE editor, Elwin Smith, and two anonymous reviewers for helpful comments. 


\section{REFERENCES}

AAFC. 2008. Distribution of cattle slaughter activity. Red Meat Market Information Livestock Market Review. Ottawa: Market and Industry Services Branch, Agriculture and Agri-food Canada. http://www.agr.gc.ca/redmeat/almrt24cal_eng.htm (accessed August 29, 2010).

Azzam, A. 1997. Measuring market power and cost-efficiency effects of industrial concentration. The Journal of Industrial Economics 45 (4): 377-86.

Azzam, A. and D. Anderson. 1996. Assessing competition in meatpacking: Economic history, theory and evidence. U.S. Department of Agriculture, GIPSA-RR 96-6.

Azzam, A. and E. Pagoulatos. 1990. Testing oligopolistic and oligopsonistic behaviour: An application to the U.S. meat-packing industry. Journal of Agricultural Economics 41 (3): 362-70.

Azzam, A. and T. Park. 1993. Testing for switching market conduct. Applied Economics 25 (6): 795-800.

Blackwell, J. L. 2005. Estimation and testing of fixed-effect panel-data systems. The Stata Journal 5 (2): 202-207.

CanFax. 2009. Monthly fed and slaughter cattle prices. http://www.canfax.ca/Reports/ FullSpreadsheets.aspx (accessed August 29, 2010).

Carlberg, J. G., R. J. Hogan, Jr. and C. E. Ward. 2009. Game theory application to fed cattle procurement in an experimental market. Agribusiness 25 (1): 56-69.

Church, J. and D. Gordon. 2007. Market power in the Alberta red meat packing industry. Institute of Advanced Policy Research, University of Calgary, IAPR Technical Paper 07004. http://www.iapr.ca/files/iapr/iapr-tp-07004.pdf (accessed August 29, 2010).

Cranfield, J. and E. Goddard. 1999. Open economy and processor oligopoly power effects of beef advertising in Canada. Canadian Journal of Agricultural Economics 47 (1): 1-19.

Diewert, W. E. 1973. Functional forms for profit and transformation functions. Journal of Economic Theory 6 (3): 284-316.

Hansen, L. P. 1982. Large sample properties of generalized method of moments estimation. Econometrica 50 (4): 1029-54.

Keene, M. P. and D. E. Runkle. 1992. On the estimation of panel data models with serial correlation when instruments are not strictly exogenous, Journal of Business and Economic Statistics 10 (1): $1-29$.

Kesavan, T. and B. Buhr. 1995. Price determination and dynamic adjustments: An inverse demand system approach to meat products in the United States. Empirical Economics 20 (4): 681-98.

Koontz, S. and P. Garcia. 1997. Meat-packer conduct in fed cattle pricing: Multiple-market oligopsony power. Journal of Agricultural and Resource Economics 22 (1): 87-103.

Love, A. 2005. An investigation of the effects of BSE on the Canadian cattle and beef markets. Summaries of economic reports prepared for the competition bureau in its examination of cattle and beef industry pricing patterns before and since the onset of BSE. http://www.cb-bc.gc.ca/eic/site/cbbc.nsf/eng/01889.html\#love (accessed August 29, 2010).

MacLachlan, I. 2001. Kill and Chill: Restructuring Canada's Beef Commodity Chain. Toronto: University of Toronto Press.

Morrison Paul, C. J. 2001. Market and cost structure in the U.S. beef packing industry: A plant-level analysis. American Journal of Agricultural Economics 83 (1): 64-76.

Murray, B. 1995. Measuring oligopsony power with shadow prices: U.S. markets for pulpwood and sawlogs. The Review of Economics and Statistics 77 (3): 486-98.

Muth, M. and M. Wohlgenant. 1999. Measuring the degree of oligopsony power in the beef packing industry in the absence of marketing input quantity data. Journal of Agricultural and Resource Economics 24 (2): 299-312.

Newey, W. K. and K. D. West. 1987. A simple positive semi-definite heteroskedasticity and autocorrelation consistent covariance matrix. Econometrica 55 (4): 703-708. 
NFU. 2008. Presentation to the competition policy review panel. National Farmers Union. http:// www.ic.gc.ca/eic/site/cprp-gepmc.nsf/vwapj/National_Farmers.pdf/\$FILE/National_Farmers. pdf (accessed August 29, 2010).

Quagrainie, K., J. Unterschultz, M. Veeman and S. Jeffrey. 2003. Testing for processor market power in the markets for cattle and hogs in Canada. Canadian Journal of Agricultural Economics 51 (3): 397-411.

Schroeder, T. and C. Ward. 2006. Price discovery and captive supply implications for Alberta beef producers and feeders. NAIBER Information Bulletin No. 12-2006-1.

Schroeter, J. 1988. Estimating the degree of market power in the beef packing industry. The Review of Economics and Statistics 70 (1): 158-62.

Statistics Canada. 2007. North American industry classification system (NAICS) - Canada. Catalogue no. 12-501-XIE.

Statistics Canada. 2008. Table 290009 V754881 capital expenditures, meat product manufacturing. http://dc2.chass.utoronto.ca.proxy2.lib.umanitoba.ca/cgi-bin/cansimdim/c2_retrieveData.pl? seriescart $=754881 \&$ lang $=$ undefined $\&$ actionreq $=\& a=\&$ bdate $=1991-01-01 \&$ edate $=2003-01-01 \&$ display $=$ timeseries\&orient_tm $=$ cols\&format $=$ plain\&onegraph $=0 \&$ data_quality $=$ no $\quad($ accessed December 15, 2008).

Statistics Canada. 2009a. Annual survey of manufactures and logging. http://www.statcan.gc. $\mathrm{ca} /$ cgi-bin $/ \mathrm{imdb} / \mathrm{p} 2 \mathrm{SV}$.pl?Function $=$ getSurvey\&SDDS $=2103 \&$ lang $=$ en $\& \mathrm{db}=\mathrm{imdb} \& \mathrm{adm}=8 \&$ dis $=2$ (accessed August 29, 2010).

Statistics Canada. 2009b. Summary of changes over time - annual survey of manufactures and logging (ASML). http://www.statcan.gc.ca/cgi-bin/imdb/ p2SV.pl?Function=getMainChange\& SurvId $=2103 \&$ SurvVer $=6 \& I n s t a I d=14033 \&$ SDDS $=2103 \&$ lang $=$ en $\& \mathrm{db}=\mathrm{imdb} \& \mathrm{adm}=8 \& \mathrm{dis}=2$ (accessed August 29, 2010).

Stock, J. and M. Watson. 2007. Introduction to Econometrics, 2nd ed. Boston: Pearson-Addison Wesley.

Ward, C. 2002. A review of causes for and consequences of economic concentration in the U.S. meatpacking industry. Current Agriculture, Food \& Resource Issues 3: 1-28. 